\title{
The Savage Case
}

\section{Week three: Mrs Savage's side of the story}

Last week the Tower Hamlets District Health Authority inquiry into allegations of incompetence against Mrs Wendy Savage, the London Hospital obstetrician, began to hear Mrs Savage's side of the story. Before she embarked on her evidence the inquiry heard from Mr Gordon Bourne, regional assessor for the confidential inquiry into maternal deaths, who at the health authority's request had reviewed the five cases giving rise to the charges against Mrs Savage. Mr Bourne said that Mrs Savage's management was out of line with acceptable medical practice as laid down in the standard textbooks and standard teaching. Mr Trevor Beedham, a consultant colleague of Mrs Savage's at the London Hospital, outlined for the panel his involvement in the events leading up to Mrs Savage's suspension last April. As chairman of the division of obstetrics and gynaecology, he said that after discussions with colleagues and junior staff and after taking advice from Professor Sidney Watkins, chairman of the hospital's medical council, from $\mathrm{Mr}$ Sotiris Argyrou, then the district administrator, and from his Medical Protection Society adviser, he had seen Mrs Savage about the case of $\mathrm{AU}$, in which the baby had died eight days after birth. On 21 May 1984 he had written to Dr Jean Richards, the district medical officer, with details of the case.

Mr David Oram, another consultant at the London, said that he covered for Mrs Savage when she was away but did not ask her to cover for him. This was because she had no involvement with Whitechapel, where the other four consultants were located, and because it was convenient for Mr Beedham and himself to cover for each other. He said he had no anxieties about her covering his practice and felt she would have covered it as he would have wished. He added that he would not be happy in all circumstances to apply her practices and had on occasion found himself in difficult circumstances. Nevertheless, he would not have found this sufficient reason to withdraw his agreement to cover for her. He said he had been shocked to hear she had been suspended.

Opening the case for Mrs Savage, her counsel, John Hendy, quoted from her statement to the chairman of the health authority, which spoke of "the extraordinary and unprecedented manoeuvres which have led to my suspension." It was accepted, he said, that standards of ideal management were not reached in these cases, and errors were made. But the evidence in these cases was a million miles away from demonstrating incompetence.

Mrs Savage told the hearing that she had begun to practise obstetrics in 1964 in Nigeria. She had been a registrar at the Royal Free Hospital, a locum lecturer at the London Hospital, and was appointed senior lecturer at the London in 1977, under Professor Peter Huntingford. She contrasted her views on obstetrics, which she described as the "optimistic" approach-that everything is normal until something goes wrong - with the "pessimistic" approach of those at the opposite end of the spectrum-that no pregnancy is normal except in retrospect. She said there were male and female philosophies of childbirth: men, who were onlookers and bystanders, felt they had to do something about the pain and the labour. Women understood that there were worse things than pain and that going through the experience of labour was an important part of how a woman functions. None of the consultants at the London, however, was particularly interventionist. She, $\mathrm{Mr}$ Beedham, and Mr Oram were similar in their approach, except in the management of breeches. She felt that one should weigh up all the factors before deciding to intervene, but whether one should decide for a trial of labour or a caesarean section was not something she was dogmatic about.

Commenting on the description of her by Professor Dennis, who had given evidence the previous week, as having been "isolated" at the Mile End site of the London Hospital, she said that the other four consultants were at Whitechapel and it appeared to her that they would get together and make a decision and she would be presented with a fait accompli. In that sense, she was isolated from the decision making process. At the time she had assumed this was not deliberate, but looking back on it she was not so sure.

Mrs Savage told the inquiry that she had been "very upset" by $\mathrm{Mr}$ Beedham's letter of 21 May to Dr Richards. She saw Professor Watkins, who told her his advice to Mr Beedham had been to "have nothing further to do with it." In September 1984, after Dr Richards's secretary had asked her secretary for the AU case notes, she said that she telephoned Dr Richards, who told her she was thinking of setting up an inquiry under HM 61/112. She wrote to the Medical Defence Union, but was advised by a solicitor at Hempsons (the MDU's solicitors) that she should do nothing because "in his experience these things were always happening to doctors and they usually blew over." Only in April 1985, when she was suspended, did she realise that other cases had also been investigated.

Moving on to her handling of the cases, Mrs Savage said the SP case was highly unusual. She agreed with the underlying criticism: that one did not give oxytocin in the second stage of labour in a breech presentation. She had never done it before and did not think she had done it since, not having had the particular combination of circumstances. SP was a 6 feet 1 inch tall woman, with a not very large baby; she had apparently reached full dilatation but had no desire to push and the breech was not descending. Neither mother nor baby was distressed, and the baby was not in danger.

In the LG case, where the baby was stillborn as a result of intrauterine growth retardation, Mrs Savage said she did not believe she had been wrong in allocating the case for shared care with a general practitioner who had been her senior house officer and in whose ability she had confidence. What had happened was an administrative slip up: the patient had not seen the consultant when she should have done, because the midwife had redated her and, thinking her less than 36 weeks' gestation, had given her a two week appointment instead of a one week one. Mrs Savage accepted that she was at fault, but she thought it was not so much in delegating as in not writing down every possible reason for the baby's apparently small size.

In the case of DL, a twin pregnancy complicated by anaemia and pre-eclampsia and where there was a breech presentation, Mrs Savage, who was on study leave at the time of delivery, said she had not spoken about the case to $\mathrm{Mr}$ Oram, who was covering for her, because the anaemia was being actively managed, and the preeclampsia had not been severe up to 1 July. On 5 July, before going to her course, she had discussed the case with her senior house officer, Dr Spankie, and decided that DL ought to be delivered. She had not examined the patient but had written "for induction today" because the last time DL had been palpated the breeches were high. It seemed likely she could deliver vaginally quite quickly if the cervix were favourable and if the breech could be pushed down into the pelvis. What Mrs Savage really meant, she said, was that she thought she should be delivered that day and hoped she could be delivered vaginally. Mr Nysenbaum, a senior registrar, was on duty and she had asked Dr Spankie to tell him to "sort it out," meaning that he should examine the patient and take the appropriate action, depending on his findings. He should have known that she had not examined the patient, because if she had done so it would have appeared in the notes. But, in retrospect, she saw that she should have spoken to $\mathrm{Mr}$ Nysenbaum herself.

CLARE DYER, solicitor and legal journalist, London. 